\title{
SUPERPLASTICALLY FORMED FRICTION STIR WELDED TAILORED ALUMINUM AND TITANIUM BLANKS FOR AEROSPACE APPLICATIONS
}

\author{
Daniel SANDERS ${ }^{1,2}$, Paul EDWARDS ${ }^{1,2}$, Glenn GRANT ${ }^{3}$, Mamidala RAMULU ${ }^{2}$, \\ Anthony REYNOLDS ${ }^{4}$ \\ ${ }^{1}$ BOEING Company - P.O. Box 3707 MS5K-63 - SEATTLE, WA - USA \\ daniel.g.sanders@boeing.com \\ ${ }^{2}$ University of Washington - SEATTLE, WA - USA \\ ${ }^{3}$ Pacific Northwest National Laboratories - RICHLAND, WA - USA \\ ${ }^{4}$ University of South Carolina - COLUMBIA, SC - USA
}

\begin{abstract}
The purpose of this study was to develop a specialized Friction Stir Welding process for superplastic grade aluminum alloy $5083-\mathrm{SP}$ and titanium alloy $6 \mathrm{Al}-4 \mathrm{~V}$, in thickness of 1.5 to $4 \mathrm{~mm}$, such that the butt welded nugget would have equal superplastic forming (SPF) characteristics as the parent sheet material The concept of using tailored blanks for the SPF process is proposed which will allow the joining of multiple pieces to fabricate much larger monolithic components than has been possible in the past. Another benefit of using tailored blanks for SPF applications was found to be a more closely matched blank shape relative to the plan size of the SPF forming die. However, shape of the tailored blanks is critical in SPF of a component. An example of this might be the case where a polygon shaped blank might work in order to reduce the amount of material used, but a rectangular blank is currently used because a tailor made blank with superplastic joints was not found to be technologically feasible. Upon development of a suitable FSW process for each material, the technology was applied to fabricate full scale test components representing a generic jet engine nacelle Lipskin.
\end{abstract}

Keywords :

Superplastic Forming, SPF, Friction Stir Welding, FSW, titanium, 6Al-4V, aluminium, 5083, tailored blank, nacelle, aerospace, laminar flow, weight reduction, fuel savings, monolithic assembly.

\section{INTRODUCTION}

The increasing cost of Jet A-1 fuel (Fig. 1) in recent years has compelled Boeing to make changes in the materials and design used for new airplanes, such as the 787 Dreamliner. Carbon Fibber Reinforced Composites (CFRC) are quickly becoming the materials of choice for large passenger jetliner airplane structures such as the fuselage, empennage and wings. While the weight, strength, fatigue and passenger comfort advantages with these materials have allowed for improvements in component design and aircraft performance, the largest pitfall with CFRC has been found to be that it is much less compatible with traditional aerospace aluminium alloys for galvanic corrosion, thermal expansion and electro-magnetic effects (EME) issues. Titanium alloys have properties far more advantages in terms of their compatibility with CFRC and this has led to titanium becoming the material of choice for many applications. SPF- and hot forming of titanium have emerged as two of the most 
significant processes for the fabrication of large monolithic sheet metal parts that have historically been fabricated using aluminium built up assemblies [1-2].

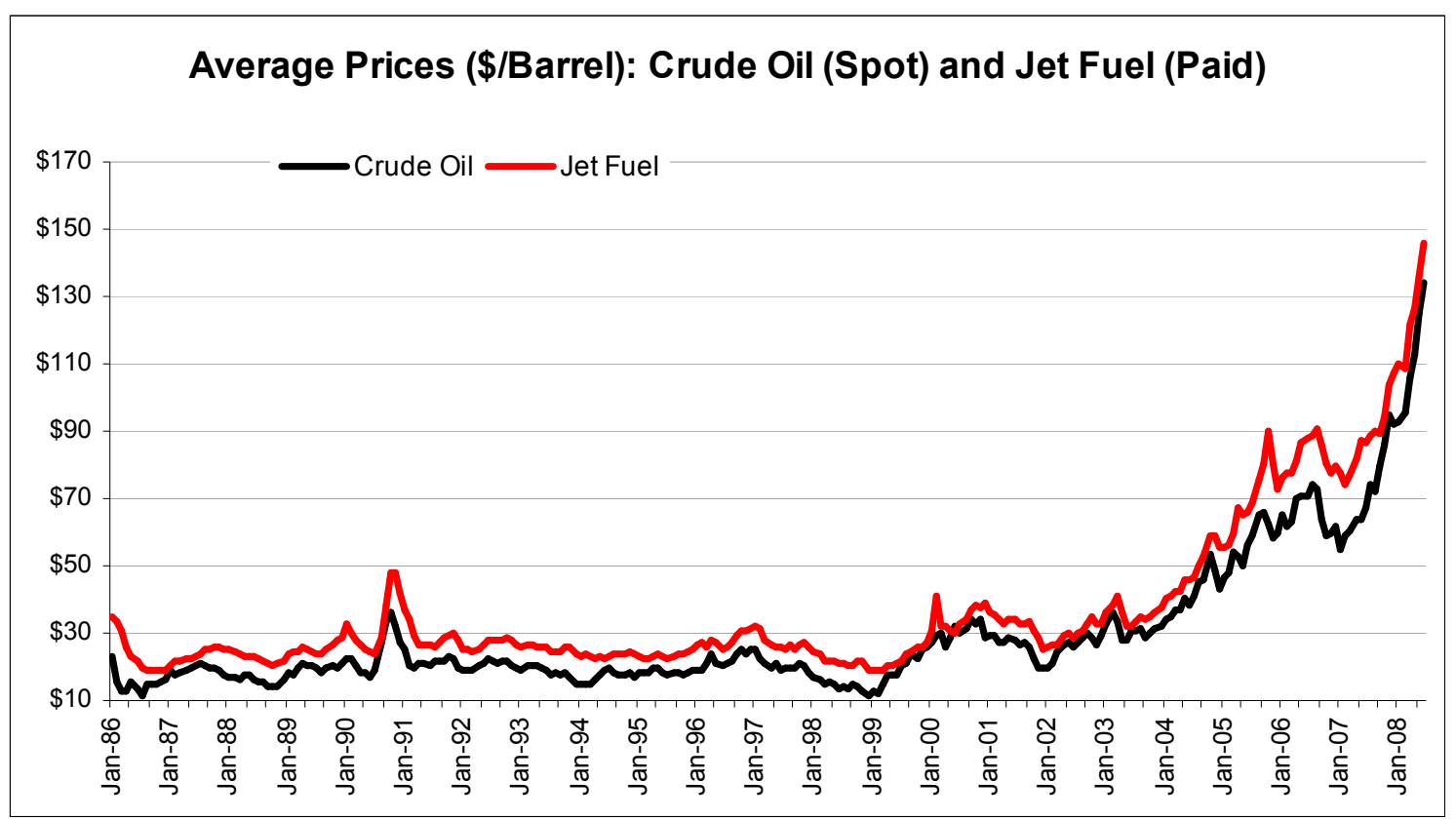

Figure 1. The price of crude oil and Jet A-1 fuel (U.S. dollars) vs. time. Source: U.S. Dept. of Commerce, July, 2008.

Aside from being compatible with CFRC materials, the advantages with using titanium SPF parts include:

- $\quad$ The ability to form complex curvatures and compound contours.

- $\quad$ No spring back from forming and little or no residual stresses.

- $\quad$ The need for only a single machined die surface vs. matching halves.

- Fewer tools required with little or no assembly.

- $\quad$ Fewer holes to drill and reduces the use of fasteners.

- $\quad$ Outside mould lines can be very smooth to reduce aerodynamic drag (achieve laminar flow).

- Integral stiffening beads can be used to avoid separate fastened stiffeners.

- With tailored blanks, considerable scrap can be avoided, decreasing the buy-tofly ratio.

There are considerations that must be taken into account when using SPF:

- $\quad$ Thinning of the sheet during forming must be carefully understood.

- Close coordination is required between the engineering and tool designers.

- Not all metal alloys exhibit superplasticity.

The 737-300 was the first Boeing airplane to convert a riveted aluminium built-up structure used as an Access Door for the Auxiliary Power Unit (APU) into a much simpler assembly that utilizes a single SPF 7475 aluminium formed frame (Fig. 2) [3]. The SPF design uses integral formed "hat" sections in a circuitous pattern to replace hydropress formed detail parts that are subsequently drilled and riveted together. The SPF version eliminated 25 detail parts and 137 holes/rivets. A weight savings of $9 \%$ and a cost savings of $75 \%$ were achieved. Because the SPF details are built to higher precision tolerances, the quality problems 
experienced in building the built-up assembly were completely eliminated. In addition to the more efficient design, the fabrication was simplified through the use of laser trimming and automated fastening equipment. Over 2,000 of these doors are currently in service today and the same design has been used on subsequent variants of the 737 airplane family. Two Service Doors on the 777 are also in production.

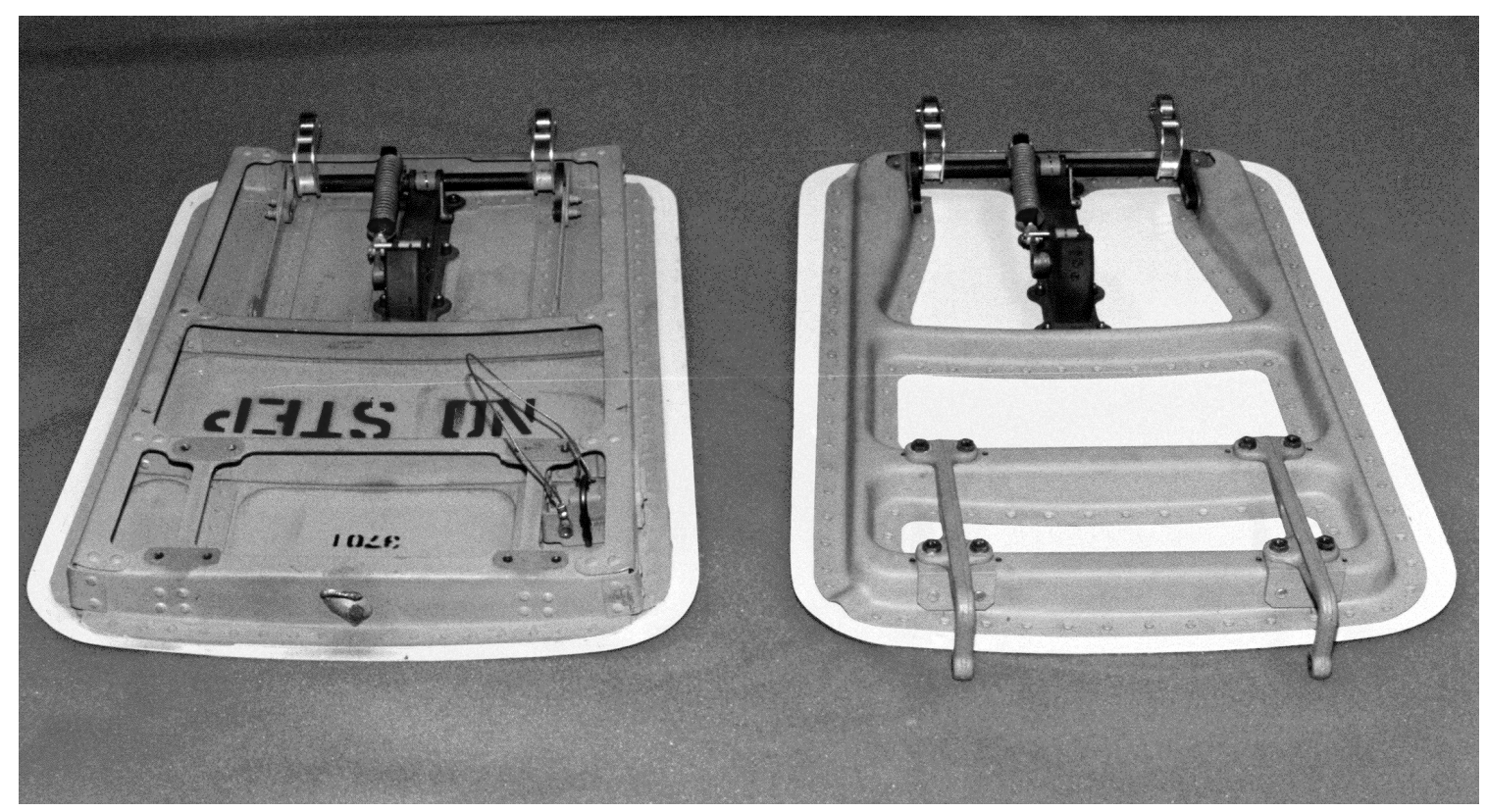

Figure 2. The built-up aluminium APU Access Door is shown on the left and the SPF monolithic design is shown on the right.

While implementation of the 737 APU Access Door was a tremendous achievement, it quickly became clear that far greater efficiencies and cost savings could be realized by focusing on larger assemblies. Over the past 20 years, the use of SPF at Boeing has gradually transitioned to ever increasing sizes, with many of the parts that are currently in production being formed using the largest (widest and/or longest) sheets of titanium that are available from the mills.

By the year 2000, the limitation on the size of sheet titanium had become a critical barrier to overcome in order to enable the fabrication of much larger monolithic parts, such as a single piece jet engine Inlet for a Nacelle. Therefore, studies were begun by conducting UniversityIndustry collaborative research to find advanced methods of fabricating tailored blanks for SPF using many different joining methods. After substantial testing of many fusion welding techniques failed to produce a joint that could withstand the amount of stretching encountered in typical SPF parts without tearing, a study was begun to develop the titanium Friction Stir Welding (FSW) process and to find a way to make an FSW weld bead with highly superplastic properties [4]. At this time, FSW had been invented and developed by The Welding Institute (TWI) for aluminium alloys only a few years earlier [5] and no papers had been published on combining FSW with SPF for titanium.

The development of the FSW process for titanium 6Al-4V in standard and fine grain material types yielded an excellent manufacturing process that could produce tailored blanks with joints of equal superplasticity to the parent sheet, which broke the size barrier for producing very large parts. However, the cost of developing the forming and post-forming machines, 
processes, tooling, material handling equipment and various other technologies using titanium as the experimental material became prohibitively expensive. In order to reduce the cost of development, a process for FSW and SPF of the much less expensive 5083-SP was required to substitute test pieces made from aluminium for the expensive titanium.

\section{DEVELOPMENT OF FSW-SPF FOR 5083-SP}

The earlier development work that was reported [4], had identified some of the key parameters affecting the superplasticity of titanium FSW joints were the spindle speed (rpm), the feed rate $(\mathrm{mm} / \mathrm{sec})$ and the pin tool geometry. . For the 5083-SP testing a commercially available pin tool was chosen that had been designed for general use in FSW of aluminium sheet metal. The pin tool had a shoulder diameter of approximately $20 \mathrm{~mm}$. For the initial FSW trials, the process parameters were chosen as a "best guess" from FSW data developed for similar aluminium alloys of similar thickness.

SPF experimental parameters provided by Pacific Northwest National Laboratories were used during all tests. These parameters had been developed for fabricating fusion welded tailored SPF blanks for the automotive industry during an earlier investigation [6]. The forming temperature used for the superplasticity tests was $530{ }^{\circ} \mathrm{C}+/-25^{\circ} \mathrm{C}$ and the target strain rate was $4 \times 10^{-4} \mathrm{~s}^{-1}$. The range of SPF elongation measured independently in the parent metal and the FSW joint was found to be in a range of 20-80\% when the tests were stopped, with a target of 50 to $70 \%$ elongation over the entire length of the specimens.

In order to characterize the superplastic behaviour of FSW joints in 5083-SP aluminium, there are two values that were quantified after FSW-SPF Specimens tensile testing $[4,6]$. These values were the elongation in the weld $\left(\mathrm{e}_{\mathrm{W}}\right)$, and the elongation in the parent material $\left(\mathrm{e}_{\mathrm{P}}\right)$. For the forming evaluation, the elongation ratio $(P / W$ Ratio $)$ is calculated for each test coupon and this is used to gage the relative superplastic strain to make a comparison between the parent metal sheet and the FSW joint. Equation (1) defines the $\mathrm{P} / \mathrm{W}$ ratio, where $e \mathrm{P}$ is the superplastic elongation of the parent material and $e \mathrm{~W}$ is the superplastic elongation of FSW. A P/W Ratio of 1.00 would indicate equivalent superplastic strain and this was the target for this investigation.

\section{$\mathrm{P} / \mathrm{W}$ Ratio $=\left(e_{\mathrm{P}}\right) /\left(e_{\mathrm{W}}\right)$}

Testing of the titanium material had shown that welds made with "hotter" FSW parameters (welds made with faster spindle speeds and feed rates) showed less superplastic behaviour than welds made with comparatively "colder" FSW parameters (slower spindle rpm and feed rate). When adjusting the FSW process to develop ideal superplastic properties, it is helpful to calculate the Pseudo Heat Ratio as an indication of the relative "hot" or "cool" temperatures developed during the FSW process across the weld joint. The Pseudo Heat Ratio (PHR) is defined in equation (2), where $N$ is the spindle speed (rpm) and $f_{\mathrm{r}}$ is the feed rate $(\mathrm{mm} / \mathrm{sec})$. The units for the PHR value are meaningless, as it is meant to be simply a tool or rough gage for understanding the amount of heat developed due to the relative amount of friction developed as the pin tool interacts with the material and it is not an exact calculation. The calculated values are often manipulated proportionately to a scale that fits nicely on a data plot. Note that small changes in the spindle speed were found to have a more profound influence on the thermal energy developed during FSW than was changing the feed rate. 
One of the values of the PHR is that, once an appropriate value for $N$ has been determined at a specific $f$ r, it is a simple task to calculate a series of alternative spindle speeds and feeds that would result in approximately the same superplastic performance. However, it has been found through empirical testing that the alternative values chosen must be within about 200 rpm as the original $N$ and about $100 \mathrm{~mm} / \mathrm{s}$ for the $f_{\mathrm{r}}$ to achieve similar SPF results across the FSW for 5083 aluminium.

Butt welded FSW test panels were fabricated using a variety of mixed parameters ranging from 275 to $350 \mathrm{rpm}$ for the spindle speed and $100-150 \mathrm{~mm} / \mathrm{sec}$ for the feed rate. Test coupons (Fig. 3) were cut from the FSW test panels and tension tested using a tensile testing machine equipped with a furnace and strain control to determine the SPF performance. The $\mathrm{P} / \mathrm{W}$ ratio and Pseudo Heat Ratio were calculated after forming by measuring the amount of actual strain in the parent metal and weld lengths of the stretched coupons. The data was charted in order to observe performance and determine the optimum forming parameters.

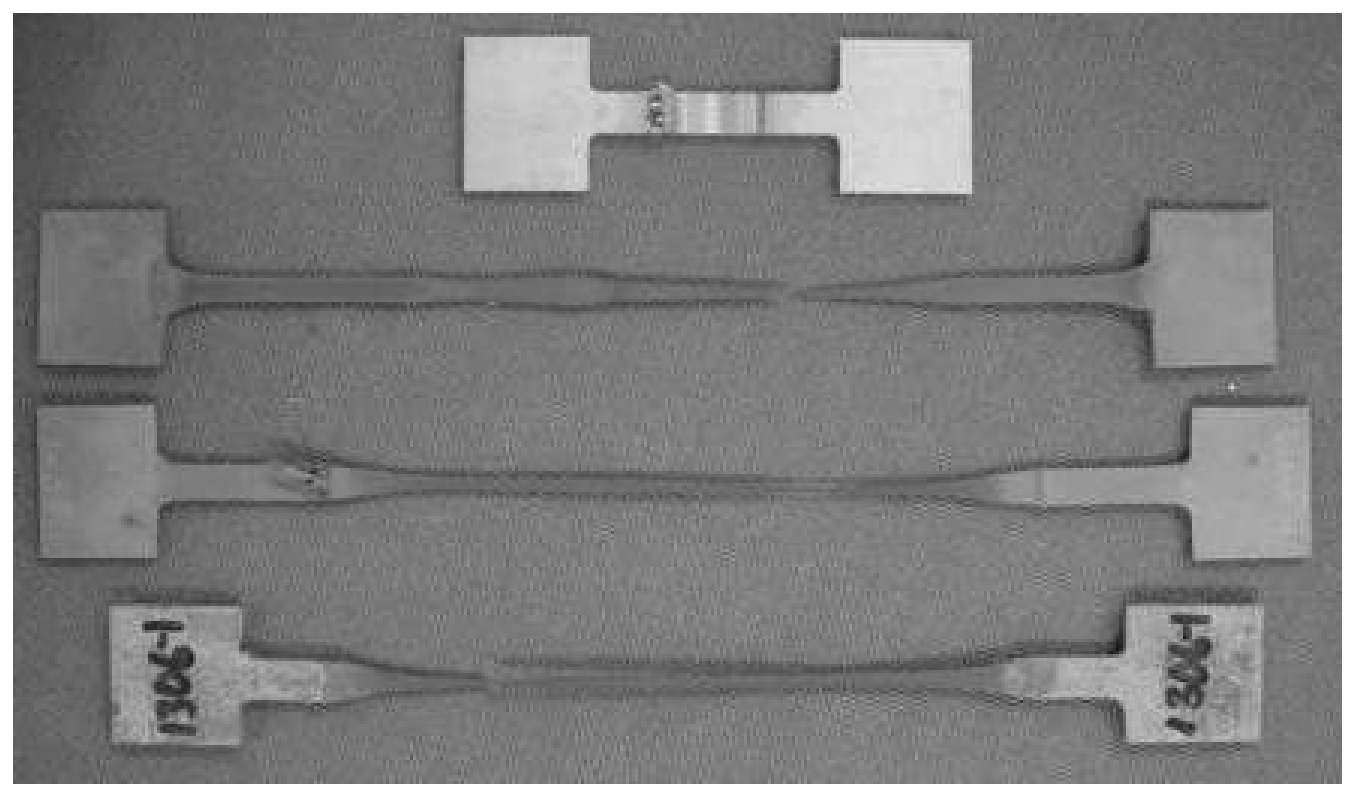

Figure 3. Butt welded FSW panels were cut into SPF tensile coupons and tested for superplastic performance at the Pacific Northwest National Laboratories.

\section{RESULTS}

The superplasticity P/W Ratios from several hot tension tests of FSW coupons with varying spindle speeds and a constant feed rate of $150 \mathrm{~mm} / \mathrm{s}$ are plotted in Figure 4 . Three separate test coupons were taken from different locations along the length of the FSW, starting from the point at which each of the butt welds were begun, to observe the effects in thermal changes across the weld joint as the pin tool heated up during its traverse.

From this data, it is seen that the desired value of the $\mathrm{P} / \mathrm{W}$ Ratio $=1$ would likely be achieved with a feed rate of $150 \mathrm{~mm} / \mathrm{s}$ at approximately $420 \mathrm{rpm}$ spindle speed. It can also be observed that increasing the spindle speed causes the FSW to be less superplastic than does decreasing it, confirming that the performance of the 5083-SP FSW process behaves in a similar fashion 
to that of the $6 \mathrm{Al}-4 \mathrm{~V}$ titanium FSW process. There is also a trend for the hotter welds, e.g. the FSW made with $N=600$ and $f_{\mathrm{r}}=150 \mathrm{~m} / \mathrm{s}$, to get much hotter as the pin progresses from its start to the end of the butt weld, which is likely due to the increasing temperature of the pin tool, which in turn generates more heat within the body of the FSW weld.

In comparison to the superplastic performance of titanium $6 \mathrm{Al}-4 \mathrm{~V}$ to $5083-\mathrm{SP}$, we can see that the aluminium material is much less responsive to changes in the $N$ and $f \mathrm{r}$ in the "colder" weld region ( 350 to $450 \mathrm{rpm}$ at $150 \mathrm{~mm} / \mathrm{s}$ ) than is the titanium FSW process. Relatively large adjustments to the FSW process seemed to have little effect on the P/W ratio for the 5083 aluminium. Whereas changes on the order of $N \sim+/-10 \mathrm{rpm}$ or $f_{\mathrm{r}} \sim+/-15 \mathrm{~mm} / \mathrm{s}$ to the stable FSW-SPF parameters around the region where $\mathrm{P} / \mathrm{W}=1.0$ will result in significant improvement or degradation in the superplasticity of the FSW titanium.

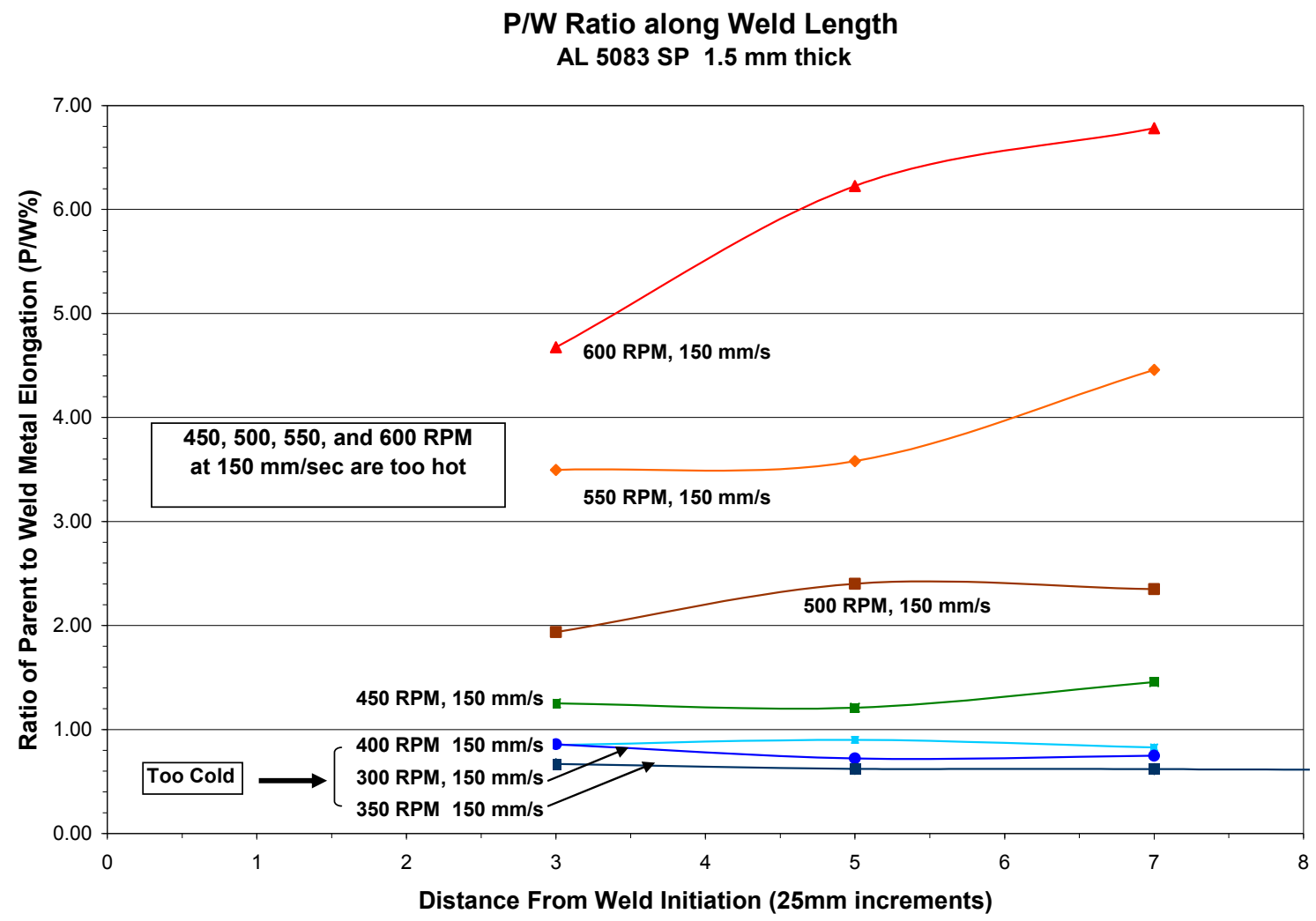

Figure 4. The P/W Ratio from superplastic formed tensile tests are plotted with FSW parameters are made from varying feed rates and rpms.

The next step for developing a suitable range of FSW process parameters with induced superplasticity in 5083-SP was to calculate the PHR for each of the superplastic formed tensile test coupons and graph it versus the P/W. This data is presented in Figure 5. A best fit curve is then calculated and plotted from the data that represents the trend of the data. From this curve, the PHR can be found at the point at which the $\mathrm{P} / \mathrm{W}$ ratio is equal to unity, which are presumably the FSW parameters for perfect superplastic performance (the parent sheet stretches at the same strain rate and flow stress as does the FSW nugget). Once the PHR is found, it becomes a simple mathematical exercise to determine values for $N$ and $f \mathrm{r}$ that are different than those tested, but would likely result in similar superplastic characteristics. 


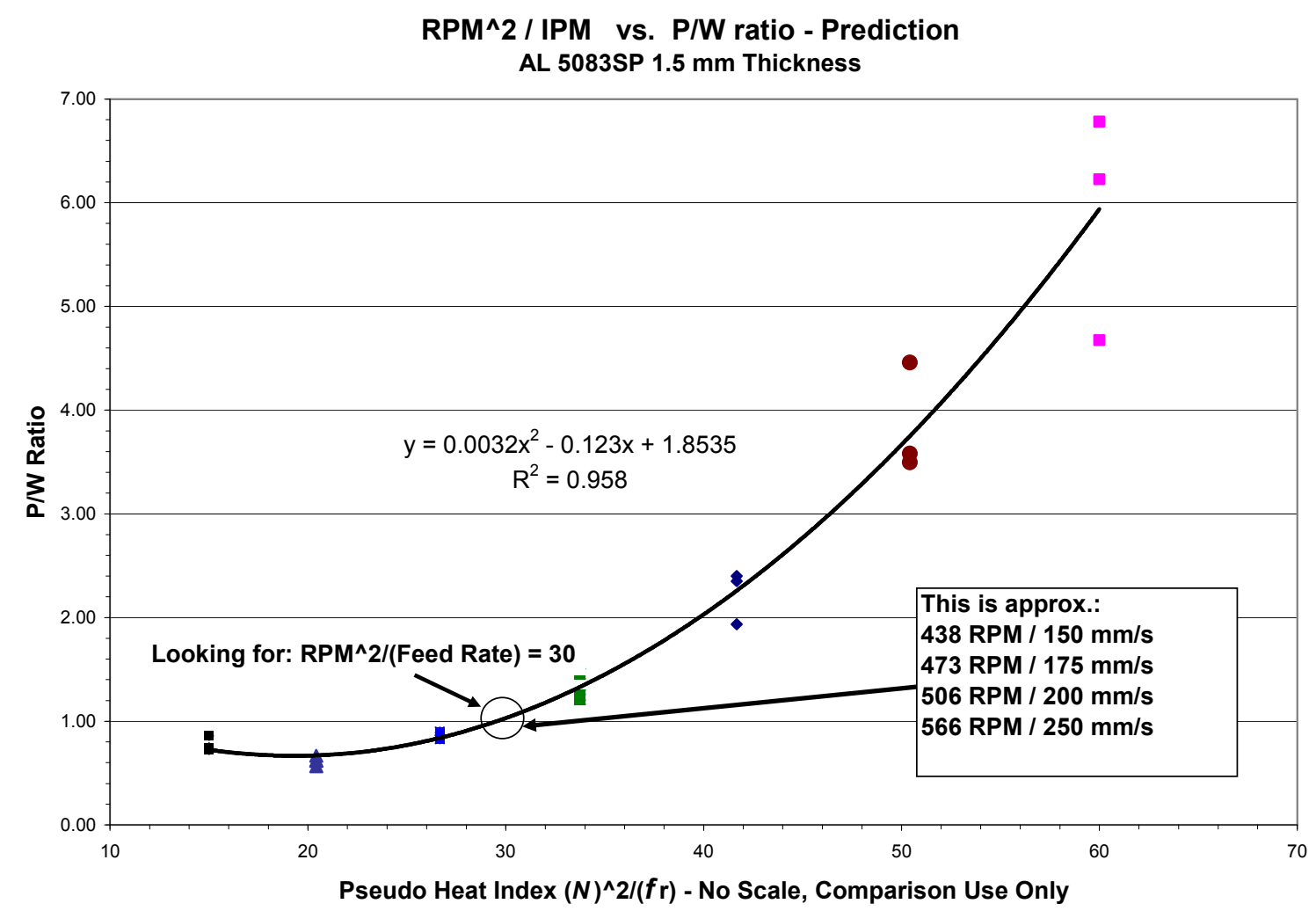

Figure 5. The P/W Ratio from superplastic formed tensile tests are plotted vs. the Pseudo Heat Ratio. From this plot, it is possible to predict SPF performance of FSWs made using slightly different FSW process variables.

Using the data generated during this study, four tailor cut segments of 5083-SP sheet metal were welded together to form a $12 \mathrm{~m}$ diameter shape, which resembled a very large donut. The blank was then superplastic formed into an aerodynamic shape emulating the leading edge of a very large jet engine Nacelle Inlet (Figure 6). Several test parts were fabricated in this fashion to be used in developing the manufacturing and post processing requirements for a similar part that was also built using titanium alloy $6 \mathrm{Al}-4 \mathrm{~V}$. A considerable cost savings was realized by using the relatively inexpensive aluminium material in place of titanium. Observations of the 5083-SP FSW joints after the part was formed showed that the thickness of the weld nugget was very close to being the same as the parent sheet. 


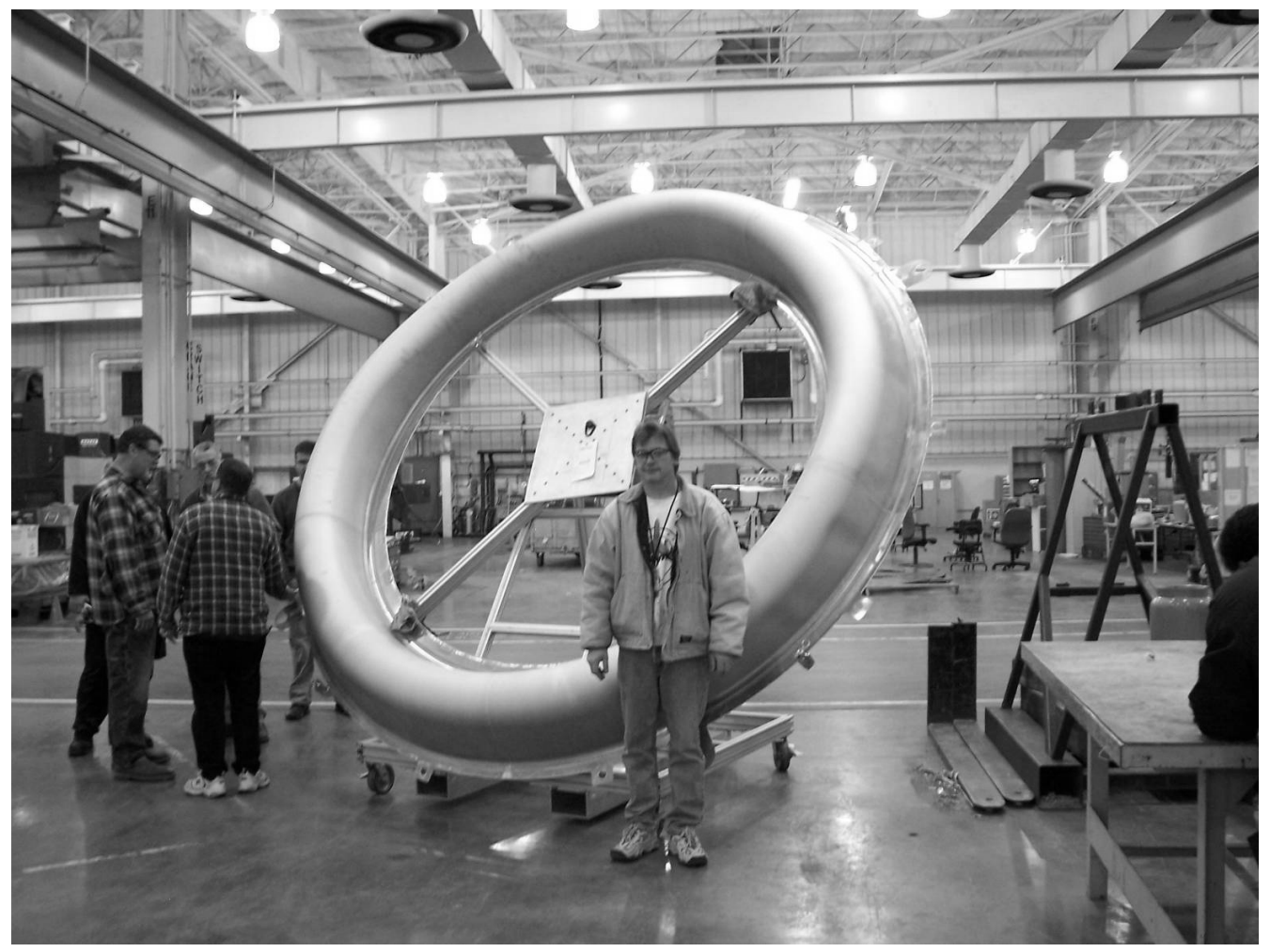

Figure 6. A fully SPF formed 5083-SP jet engine leading edge Nacelle Inlet made by FSW butt welding of four separate segmented blanks prior to forming.

\section{SUMMARY AND CONCLUSIONS}

During this study, the FSW process parameters were developed to allow the fabrication of very large monolithic structures, such as what would be required for a single piece 5083-SP aluminium Lipskin for a high bypass ratio (large diameter) jet engine. The results of the test program have shown that friction stir welding is a viable option for the fabrication of tailored blanks for use in the manufacture of SPF commercial hardware.

\section{REFERENCES}

[1] D. Sanders, M. Ramulu, P. Edwards, Superplastic Forming of Friction Stir Welds in Titanium Alloy 6Al-4V: Preliminary Results, Materialwissenschaft und Werkstofftechnik, Vol.39, No.4, , 2008, pp.353-357.

[2] D. Sanders, M. Ramulu, E. Klock-McCook, P. Edwards, A. Reynolds, T. Trapp, Characterization of Superplastically Formed Friction Stir Weld in Titanium 6Al-4V: Preliminary Results, ASM Journal of Materials Engineering and Performance, Vol. 17, No 2, 2008, pp.187-192.

[3] D. Sanders, The Current State-of-the-Art and the Future in Airframe Manufacturing Using Superplastic Forming Technologies, ICSAM 2000, Materials Science Forum, Vols. 357-359, 2001, pp. 17-22. 
[4] D. Sanders, G. Grant, M. Ramulu, E. Klock-McCook, L. Leon, G. Booker, D. Foutch, T. Reynolds, W. Tang, Superplastic Forming of Friction Stir Welded Ti 6-4 Sheet, Presented at the ASM AeroMat Conference, 2005.

[5] W. Thomas, E. Nicholas, J. Needham, M. Murch, P. Templesmith, C. Dawes, Great Britain Patent 9125978.8, 1991.

[6] R. Davies, J. Vetrano, M. Smith, S. Pitman, Mechanical Properties of Aluminium Tailor Welded Blanks at Superplastic Temperatures, Journal of Materials Processing Technology, Vol. 128, No. 1-3, 2002, pp. 38-47, 